\title{
PREPARATION OF CONDUCTING CARBON RROM RICE HUSK CHAR
}

\author{
Md. Ahiduzzaman ${ }^{a}{ }^{*}$ and A.K.M. Sadrul Islam ${ }^{\mathrm{b}}$ \\ ${ }^{a}$ Department of Agro-processing, Bangabandhu Sheikh Mujibur Rahman Agricultural University \\ Gazipur-1706, Bangladesh \\ ${ }^{\mathrm{b}}$ Department of Mechanical and Chemical Engineering, Islamic University of Technology \\ Board Bazar, Gazipur-1704, Bangladesh \\ *Corresponding e-mail: ahid72@yahoo.com
}

\begin{abstract}
Porous carbon materials have attracted interest recently as they are potential candidates for large number of applications especially in catalytic supports, battery electrodes, capacitors, gas storage and biomedical engineering applications. As porous carbons are mostly amorphous in nature, a little presence of $s^{2}{ }^{2}$ carbon structure enhances the possibility of using these carbon materials for wider applications involving electrical conductivity. Electrical conductivity of in porous acitivated carbon is increased by doping a suitable metal ion. Rice husk char is choosen in this study as precursor for preparation of conducting carbon. The produced conducting carbon exibits p-type semiconductor in character when copper, nickle, zinc and silver ions are doped. The highest electricaal conductivity of silver ion doped material is found to be $2.84 \times 10^{-2} \mathrm{mho} / \mathrm{cm}$ at $60 \%$ of ion concentration of doping solution. The results of this study conclude that rice husk char could be used for producing conducting carbon and silver ion is the better among other doping materials used.
\end{abstract}

Keywords: Rice husk char, Conducting carbon, Thermo-electric volt, Electrical conductivity

\section{INTRODUCTION}

The rice husk char is to be used as a source of clean energy and activated carbon. Moreover, it has various industrial applications. Recently, several attempts have been made to produce conducting carbon from this char ${ }^{1-2}$. Both carbon and silicon have four electrons in their outer shell and both occupy the same group in the periodic table. But the elements form a completely different range of compounds. The ranges of carbon based materials are diamond, graphite, amorphous carbon and nano-tubes etc. Carbon from biochar materials is cost effective. Silicon has achieved almost unbeatable status on electronics through know-how and control. Silicon is a unique material due to the amazing degree of control of dislocations and dopants. However, lately, demands for greater miniaturization, higher speed, lower power use, and heat dissipation are becoming hard to meet with silicon. Despite variants like porous silicon, silicon-based semiconductors are unlikely to be leaders. Silicon may not be the material of choice for some new opportunities, like electronic books. It is not the natural choice where inorganic meets biological systems, nor when the environment is hostile, whether through higher temperature or electrochemical conditions ${ }^{3}$. Porous carbon materials have attracted interest recently as they are potential candidates for large number of applications especially in catalytic supports, battery electrodes, capacitors, gas storage and biomedical engineering applications ${ }^{4-6}$. As porous carbons are mostly amorphous in nature, a little presence of $\mathrm{sp}^{2}$ carbon structure enhances the possibility of using these carbon materials for wider applications involving electrical conductivity ${ }^{7-8}$. The $\mathrm{sp}^{2}$ carbon sites in the porous carbons predominantly control the electronic and transport properties ${ }^{9}$. The objective of this study is to prepare conducting carbon from porous rice husk char under various doping materials.

\section{MATERIALS AND METHODS \\ Preparation of doped porous carbon}

The fractal mapping of activated carbon shows the internal pore. The internal pore space forces molecules to move along a fractal path shown in the Fig. 1. Therefore, foreign molecule can be doped within the pore of the activated carbon through porous structure. Appropriate doping in the carbon pores by suitable element whose atomic size matches the pore diameter is expected to bring about conductivity modulation in the carbon ${ }^{1,10-11}$.

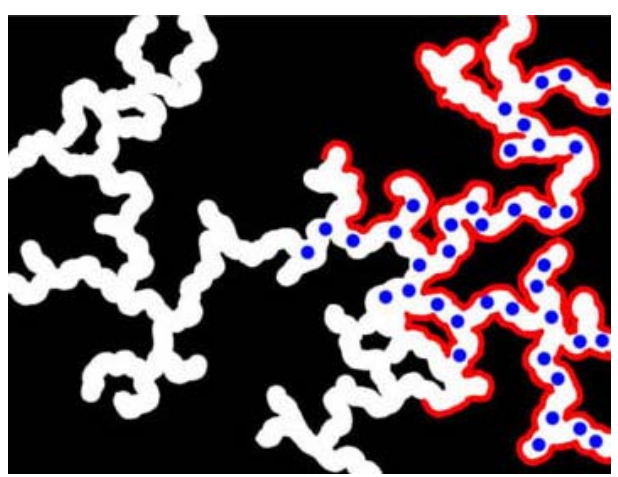

Figure 1. The fractal mapping of activated carbon ${ }^{12}$

J oumal of Mechanical Engineering, Vol. ME 43, No. 1, J une 2013

Transaction of the Mech. Eng. Div., The Institution of Eng ineers, Bangla desh 
Based on the concept shown in Fig. 1, different metal ions were doped in the porous activated carbon so that the metal could take place along inside pore space of activated carbon. In the present work the activated carbon prepared from rice husk was taken and four different types of salts were used for doping. Such salts were silver nitrate, copper chloride $\left(\mathrm{CuCl}_{2} \cdot 2 \mathrm{H}_{2} \mathrm{O}\right)$, zinc chloride $\left(\mathrm{ZnCl}_{2}\right)$ and nickel chloride $\left(\mathrm{NiCl}_{2} \cdot 6 \mathrm{H}_{2} \mathrm{O}\right)$. In this study silver nitrate salt solution is used for doping because silver has higher conductivity than copper.

One gram of activated carbon was soaked in each of four types of salt solution and kept for 24 hours. The resulting mixture was then filtered and washed with de-ionized water and dried in an oven at $105^{\circ} \mathrm{C}$. To make pellet, $5 \%$ solution of poly vinyl alcohol was added as a binder and pellets were prepared by pressing in a die of $25 \mathrm{~mm}$ diameter.

The electrical conductivity of activated carbon was also determined in this study to make a comparison with doped porous carbon. Three samples of porous activated carbon were taken to conduct this study. The samples were treated with zinc chloride, phosphoric acid and silver nitrate. The mass ratios of impregnation of zinc chloride, phosphoric acid and silver nitrate with rice husk char were considered to be $3: 1,0.725: 1$ and $0.3: 1$, respectively and the activation process was at a temperature of $700^{\circ} \mathrm{C}$ for 2 hours duration. The level of different treatment ratio was selected based on the performance of porous activated carbon reported in the doctoral thesis ${ }^{13}$.

\section{Thermo-electric volt test}

The hot probe experiment provides a simple way to distinguish between n-type and p-type semiconductors using a soldering iron and a standard multi-meter. The experiment was performed by contacting the pellet with a hot probe such as a heated soldering iron and a cold probe. Both probes were wired to a sensitive multi-meter. The hot probe was connected to the positive terminal of the meter (Model: GW Multimeter GDM-351) while the cold probe was connected to the negative terminal. A negative voltage reading indicates the p-type material and positive voltage indicates the n-type material.

\section{Conductivity test}

The electrical conductivity was measured at room temperature by the two-probe method. The pellet made from doped carbon material was placed between two pieces of copper plate. The two terminals of digital multimeter probes were connected to the two copper plates adjacent to the pellet. A slight pressure was applied on the copper plates to ensure the proper contact between copper plate and carbon pellet. Then the electrical conductivity of the sample was calculated by:

$$
\sigma=\frac{L}{R \cdot A}
$$

Where,

$$
\begin{aligned}
& \sigma=\text { electrical conductivity, } \mathrm{mho} / \mathrm{cm} \\
& \mathrm{L}=\text { thickness of sample pellet, } \mathrm{cm} \\
& \mathrm{A}=\text { area of the sample pellet, } \mathrm{cm}^{2} \\
& \mathrm{R}=\text { the resistance, Ohm }
\end{aligned}
$$

\section{RESULTS AND DISCUSSION Effect of doping by the different types of conducting material}

All four type doped pellets showed negative thermoelectric voltage during the hot probe test, i.e. all materials are $\mathrm{p}$ type material. The highest voltage showed by $\mathrm{Ag}^{++}$ion doped material as $-4.0 \mathrm{mV}$ followed by copper ion doped material $(-3.3 \mathrm{mV})$. Zinc and nickel showed same thermoelectric voltage of $-1.3 \mathrm{mV}$ (Table 1). Maiti ${ }^{10}$ reported that doping with copper chloride showed highest thermo-electric voltage $(1.5 \mathrm{mV})$ compared to zinc chloride and nickel chloride.

Table 1. Properties of different types of conducting carbon

\begin{tabular}{ccc}
\hline $\begin{array}{c}\text { Type of } \\
\text { doping }\end{array}$ & $\begin{array}{c}\text { Thermoelectric } \\
\text { voltage in mV }\end{array}$ & $\begin{array}{c}\text { Semiconductor } \\
\text { types }\end{array}$ \\
\hline $\mathrm{Cu}^{++}$ & $3.3(-\mathrm{ve})$ & $\mathrm{p}$ \\
$\mathrm{Ni}^{++}$ & $1.3(-\mathrm{ve})$ & $\mathrm{p}$ \\
$\mathrm{Zn}^{++}$ & $1.3(-\mathrm{ve})$ & $\mathrm{p}$ \\
$\mathrm{Ag}^{++}$ & $4.0(-\mathrm{ve})$ & $\mathrm{p}$ \\
\hline
\end{tabular}

A simple explanation of the experiment is that whenever a hot probe is placed on the sample surface, the carrier near the probe gain kinetic energy and moves away from the probe. As a result, deficiency of charges is created at the site while the other probe placed in cold region all charges are present, then a potential difference is created between the probes. If the hot positive terminal is placed on surface majority with negative charges then the negative charges moves away after gaining the thermal energy and deficiency of negative charges created. This phenomenon is reflected on the meter reading showing positive voltage. It implies that the material is n-type. If the opposite phenomenon is observed then it implies that the material is p-type. As silver ion doped material showed higher thermo-electric volt so the effect of different concentration of silver ion the electric conductivity of the doped materials are discussed in next section. 


\section{Effect of silver ion concentration on electrical conductivity of doped carbon}

The results from Table 1 indicate that among all types of doped carbon, silver doped material shows maximum thermo-electric voltage. So the conductivity test was done by doping silver ion in rice husk porous carbon in the form of their soluble salts at different concentration. The salt solution was prepared at different ratio with carbon. The ratios of silver nitrate salt and carbon were considered to be $0.20: 1$ to $0.80: 1$ (Salt:Carbon) by mass. The activated carbon doped using different ratio of silver salts and the conductivity variation is shown in Fig. 2.

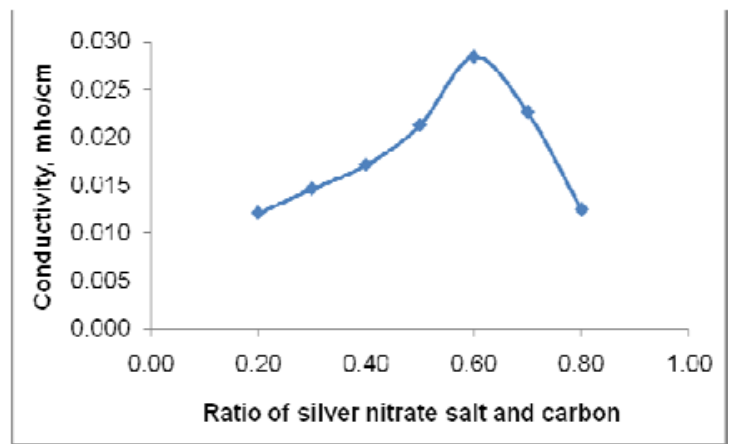

Figure 2.Variation of conductivity with silver ion doped material

The results showed that an increasing trend of conductivity with the concentration of silver ion solution and it reached a peak point at around $60 \%$ of ion doping solution. The peak conductivity was fount to be $2.84 \times 10^{-2} \mathrm{mho} / \mathrm{cm}$. The conductivity of the material was decreased with further increase of concentration of doping solution. The reason of decrease of conductivity may be due to redissolution of silver ion in the solution or breakage of ionic path inside the activated carbon moiety. Maiti ${ }^{1}$ reporetd that the electrical conductivity of silicon doped activated carbon from rice husk char is $3.57 \times 10^{-3}$ $\mathrm{mho} / \mathrm{cm}$. Maiti ${ }^{10}$ also reported that the copper ion dopped material prepared from activated carbon from jute stalk is around $1.5 \times 10^{-2} \mathrm{mho} / \mathrm{cm}$. It is reported that activated carbon without doped also showed electriocal conductivity. Hence electrical conductivity of the activated carbon are discussed in next section for a comparison with doped porous carbon.

\section{Electrical conductivity of activated carbon}

The electrical conductivity of three types of activated carbons are found to be $2.44 \times 10^{-3} \mathrm{mho} / \mathrm{cm}$, $5.91 \times 10^{-3} \mathrm{mho} / \mathrm{cm}$ and $8.30 \times 10^{-3} \mathrm{mho} / \mathrm{cm}$ for zinc chloride, phosphoric acid and silver nitrate impregnated activated carbon (Table 2). The conductivity of phosphoric acid activated carbon from rice husk is $3.177 \times 10^{-4} \mathrm{mho} / \mathrm{m}$ reported by Kennedy ${ }^{2}$.
In the present study the electrical conductivity of Phosphoric acid activated carbon is higher than that of Kennedy ${ }^{2}$ due to chemical and thermal treatment of the rice husk before activation ${ }^{13}$. Silver nitrate activated carbon shows higher electrical conductivity as well.

Table 2. Electrical conductivity of rice husk char activated carbon

\begin{tabular}{lc}
\hline $\begin{array}{l}\text { Type of activation } \\
\text { agent }\end{array}$ & $\begin{array}{c}\text { Electrical conductivity, } \\
\text { mho/cm }\end{array}$ \\
\hline a. Zinc chloride & $2.44 \times 10^{-3}$ \\
b. Phosphoric acid & $5.91 \times 10^{-3}$ \\
c. Silver nitrate & $8.30 \times 10^{-3}$ \\
\hline
\end{tabular}

\section{CONCLUSION}

Porous activated carbon shows electrical conductivity. It might be occured due to activation agent used in the process of activation of carbon. When a suitable metal ion is doped in the activaated carbon then the electrical conductivity is further increased. The conducting carbon from rice husk exibits p-type semiconductor in character when copper, nickle, zinc and silver ion are doped in activated carbon from rice husk. Silver ion doped material shows higher thermo-electric volt among different dopants. Electrical conductivity increases with increase in ion concentration. The highest electrical conductivity of silver ion doped material is found to be $2.84 \times 10^{-2} \mathrm{mho} / \mathrm{cm}$ at $60 \%$ of ion concentration of doping solution. Whereas, the electrical conductivity of silver nitrate activated carbon is found to be $8.30 \times 10^{-3} \mathrm{mho} / \mathrm{cm}$. The results of this study conclude that rice husk char can be used for producing conducting carbon and silver ion doped material performs better among other doping materials used in this study.

\section{REFERENCES}

[1] Maiti, S., Banerjeea, P., Purakayasthaa, S. and Ghosh, B., 2008. "Silicon-doped carbon semiconductor from rice husk char." Materials Chemistry and Physics. Vol. 109, Issue 1, pp. 169173.

[2] Kennedy, L.J, Vijaya, J. J. and Sekaran, G., 2004. "Electrical conductivity study of porous carbons derived from rice husk." Department of Environmental Technology, Central Leather Research Institute, Adyar, Chennai, Tamil Nadu, India. http://acs.omnibooksonline.com

/data/papers/2004_E060.pdf, accessed on 09.02.10

[3] Stoneham, M., 2004. "Electronics in carbon country.” Nature Materials 3, 3-5.

[4] Farag, H.; Whitehurst, D.D. and Mochida, I., 1998. "Synthesis of active hydrodesulfurization carbonsupported Co-Mo catalysts." Relationships between

J oumal of Mechanical Engineening, Vol. ME 43, No. 1, J une 2013 
preparation methods and activity/selectivity'. Ind Eng. Chem. Res. (1998), 37, 3533-3539.

[5] Quinn, D. F. and Ragan, S., 2000. "Carbons Suitable for Medium Pressure (6.9 MPa) Methane Storage.” Adsorp. Sci. Tech., 18, 515-527.

[6] Frackowiak, E. and Begiun, F., 2001. "Carbon materials for the electrochemical storage of energy in capacitors.” Carbon, 39, 937-950.

[7] Robertson, J., 1991. "Hard Amorphous (DiamondLike) Carbons.” Prog. Solid State Chem. 21, 199-333.

[8] Fusco, G.; Tagliaferro, A.; Milne, W. I. and Robertson, J., 1997. "Paramagnetic centres in tetrahedral amorphous carbon." Diamond Relat. Mater, 6, 783-786.

[9] Chhowala, M.; Robertson, J.; Chen, C. W.; Silva, S.R.P.; Davis, C.A.; Amaratunger, G.A.J. and Milne, W.I., 1997. "Influence of ion energy and substrate temperature on the optical and electronic properties of tetrahedral amorphous carbon (ta-C) films.” J. Appl. Phy. 81, 139-145.

[10] Maiti, S., 2007. "Studies and Investigation of Value Added Products from Agricultural Wastes." $\mathrm{PhD}$. Thesis. Advanced Materials and Solar Photovoltaic Division, School of Energy Studies, Jadavpur University, India.

[11] Schewe, P.; Riordon, J. and Stein, B., 2002. "Fractal carbon nanopore network." AIP bulletin of Physics news no. 578\#1.

[12] http://www.aip.org/png/2002/151.htm, accessed on 25.08.11.

[13] Ahiduzzaman, M., 2011. "Studies and Investigation on Extraction of Energy and Value Added Products from Rice Husk.” Ph.D. thesis, Department of Mechanical and Chemical Engineering, Islamic University of Technology (IUT), Board Bazar, Gazipur-1704, Bangladesh, September 2011. 